\title{
IMPORTÂNCIA DAS CHARGES PARA O DESENVOLVIMENTO DO PENSAMENTO CRÍTICO
}

\author{
IMPORTANCE OF CHARGES FOR THE DEVELOPMENT OF CRITICAL \\ THINKING
}

Isete da Silva Sousa ${ }^{1}$

RESUMO: Este trabalho aborda o gênero textual charge no âmbito do processo de ensinoaprendizagem e no desenvolvimento da criticidade no ambiente escolar. Com o auxílio da charge almeja-se conseguir o desdobramento de infindas possibilidades, na prática, de um ensino aprimorado e conhecimento abrangente, em especial no que diz respeito ao desenvolvimento do pensamento crítico, já que o gênero em questão expõe de forma crítica, humorística e sarcástica os mais diversos temas concernentes à sociedade. Pelo estudo de charges, utilizadas nas diversas esferas e perpassando pelo social, político, histórico e cultural, intenta-se demonstrar as suas funções, características e os recursos linguísticos responsáveis pela sua significação, fazendo o possível para incutir e aumentar, no aluno, suas capacidades linguísticas e discursivas, partindo do princípio de uma compreensão dialética e crítica da realidade atual globalizada. Diante disso, a abordagem bibliográfica foi o instrumento utilizado para contribuir para desenvolvimento deste trabalho que, dentre outros, intercala os conhecimentos fundamentados nas teorias de Bakhtin (2003), Marcuschi (2003), dentre outros.

Palavras-chave: Charge. Ensino. Criticidade.

ABSTRACT: This work addresses the textual charge genre within the teaching-learning process and in the development of criticality in the school environment. With the help of the cartoon, we aim to achieve the unfolding of endless possibilities, in practice, for an improved teaching and comprehensive knowledge, especially with regard to the development of critical thinking, since the genre in question exposes it in a critical, humorous way and sarcastic the most diverse subjects concerning the society. By studying cartoons, used in the various spheres and going through the social, political, historical and cultural, we intend to demonstrate their functions, characteristics and the linguistic resources responsible for their meaning, doing everything possible to instill and increase, in the student, their linguistic and discursive capacities, based on the principle of a dialectical and critical understanding of the current globalized reality. Therefore, the bibliographic approach was the instrument used to contribute to the development of this work, which, among others, merges the knowledge based on the theories of Bakhtin (2003), Marcuschi (2003), among others.

Keywords: Charge. Teaching. Criticality.

\footnotetext{
${ }^{1}$ Licenciatura Plena em Letras pela Universidade Federal do Amapá - UNIFAP. Com habilitação em Língua Portuguesa, Francesa e suas respectivas literaturas. Pós- graduanda em etodologia do ensino de língua portuguesa e estrangeira.E-mail: isete.luty@gmail.com.
} 


\section{INTRODUÇÃO}

Antes do surgimento da escrita, no período da Idade Antiga, as informações eram transmitidas para a sociedade através de mensageiros e por meio de rabiscos feitos em cavernas. $\mathrm{Na}$ Idade Média, com o surgimento da escrita, utiliza-se o pergaminho, sendo a carta o primeiro gênero textual introduzido no meio social.

Este sucinto preâmbulo é importante para evidenciar que a humanidade sempre procurou formas para expressar suas opiniões e divulgar notícias e, mesmo que de caráter rudimentar, as informações eram compreendidas. À medida que o homem foi evoluindo, a maneira de se comunicar também se modernizou. $\mathrm{Na}$ atualidade estão disponíveis diversos mecanismos que auxiliam na transmissão de conhecimentos e/ou informações, como, por exemplo, e-mail, outdoor, jornal, receitas, bulas, etc. Esses mecanismos são chamados Gêneros Textuais e estão presentes em todas as situações comunicativas, neste sentido,

[...] é impossível não se comunicar por algum gênero, assim como é impossível não se comunicar por algum texto. Em outros termos, a comunicação verbal só é possível por algum gênero textual. (MARCUSHI, 2003, p. 5).

Diante do exposto, o gênero textual charge foi o escolhido para embasar esta pesquisa por se tratar de um gênero que tem o poder de instigar o interesse dos alunos, pois possui um humor crítico que desperta a curiosidade, tornando assim a aprendizagem mais prazerosa, crítica e participativa, já que se trata de uma experiência de aprendizagem direcionada a uma leitura visual veiculada em jornais, internet e livros com a perspectiva de mostrar como os textos que circulam em diversos setores de comunicação escrita e ou televisionada contribuem para formar opinião e influenciam em decisões de caráter sócio-políticas de grande relevância para o país.

Sendo assim, a questão primordial é analisar a eficácia da inclusão do gênero charge no interior das instituições educativas como fonte de difusão do conhecimento e da criticidade, haja vista que as charges que circulam diariamente nas mídias abordam temas atuais ocorridos não só no país, como no mundo, fazendo-se necessário salientar a importância do emprego desse suporte pedagógico em sala de aula, uma vez que este se torna relevante para que o gênero textual circule na sociedade e influencie na natureza do gênero agregado no processo de ensino-aprendizagem, com o intuito de melhorar o ensino, levando o aluno a criticidade.

Assim, busca-se desenvolver nos estudantes a capacidade de reflexão sobre o tema proposto, partindo de que eles já conhecem o assunto e, através da interação, professor/aluno e aluno/aluno, desenvolver um novo conhecimento pautado na criticidade. Para isso é importante que se saiba o que são gêneros textuais, em que consiste o gênero charge e qual sua importância 
em sala de aula.

Todos esses pontos serão apresentados ao longo dessa pesquisa, a qual, é importante frisar, não tem por objetivo ensinar o aluno a pensar da forma considerada correta ou de uma única forma, muito menos buscar uma homogeneidade em um espaço tão heterogêneo quanto à sala de aula, mas sim o contrário. Tende a mostrar que cada gênero textual específico necessita de um olhar sobre ele, de estratégias de leitura, de retomadas de outros textos, entre outros, para que assim possam construir suas opiniões e seus conhecimentos.

\section{Gêneros textuais}

Definir gêneros textuais sempre se configurou como uma tarefa bastante difícil, talvez por esse motivo muitos teóricos tenham se dedicado ao seu estudo. A priori o termo "gênero" foi utilizado pela retórica e pela literatura com acepção designadamente literária, inclusive por Aristóteles, o qual apresentou sua clássica divisão em lírico, épico e dramático. Mas, de acordo com Machado (2005, p. I5I), a teoria de Aristóteles "trata-se apenas de uma classificação paradigmática e hierárquica, facilitada pela observação das formas no interior de um único meio: a voz”. Na perspectiva de Koch apud XAVIER e CORTEZ (2003), a principal inquietação da linguística quanto aos gêneros está inteiramente atrelada ao desafio de acompanhar as transformações sociais ao lado das quais os novos gêneros emergem e se constituem, logo que a língua se constitui em meio às práticas sociais.

Entre os muitos teóricos que trabalharam com a definição de gêneros textuais, a que se destacar o filósofo russo Mikhail Bakhtin em seu círculo de estudos, que tem embasado boa parte dos teóricos atuais sobre a questão. Atualmente, embora não haja unanimidade entre os estudiosos, os gêneros textuais são vistos como os diversos textos que circulam na sociedade e que foram sócio-historicamente produzidos, cada um na sua esfera específica e, de acordo com com as lições de Bakhtin, são divididas em dois grandes grupos: as esferas do cotidiano (familiares, intimas, comunitárias etc.), nas quais circulam as ideologias do cotidiano, e aquelas formadas por sistemas ideológicos constituídos (moral, ciência, religião, arte, política,imprensa).

Para Bakhtin, a questão dos gêneros ultrapassa a da classificação de textos segundo especificidades artístico-literárias, tal qual a divisão feita por Aristóteles. O estudioso considera que "todo campo de utilização da língua elabora seus tipos relativamente estáveis de enunciados, os quais denominamos gêneros do discurso "(BAKHTIN, 2003, p. 262). Por isso compreende-se que os gêneros são inesgotáveis, diante da criação humana, sendo assim, depreende-se que os gêneros textuais são tipos de textos que se encontram em nosso cotidiano com modelos sóciocomunicativos que abordam características de acordo com sua estrutura, enunciado e objetivos 
diretamente envolvidos em questões sociais, tecnológicas e políticas.

Por esse motivo, é importante dizer, os gêneros textuais devem ser pensados e analisados como parte da vida social, ou seja, enquanto parte da própria organização das interações humanas. Portanto, quando se pensa a respeito dos gêneros,automaticamente reflete-se acerca das relações discursivas presentes nas diversas esferas sociais, não importando que sejam os gêneros textos orais ou escritos. É válido registrar a opinião de Marcuschi (2003, p. I7) sobre os gêneros textuais no contexto social, segundo ele, a "vida diária com padrões sócio-comunicativos característicos definidos por sua composição, objetivos enunciativos e estilo, realizados por forças históricas, sociais, institucionais e tecnológicas”. Sendo assim, pode-se dizer que os gêneros surgem como uma alternativa para responder à complexidade da interação social. Marcushi (2003, p.22) afirma ainda que os gêneros enfocam-se "como ações sócio-discursivas para agir sobre o mundo e dizer o mundo, constituindo-o de algum modo". Por consequência, os textos como resultado de atividade de linguagem, agem diretamente nas formações de modalidades sócio-discursivas e compoem a estrutura utilizada como forma de organizar a linguagem e, por conseguinte a transmissão de conhecimentos e informações, pertinentes ao gênero em questão.

Neste sentido, os gêneros podem ser entendidos como uma solução para responder a complexidade da interação social,daí a importância da presença dos diversos gêneros em sala de aula.

\section{I O gênero charge}

Atualmente, é comum observar-se entre os mais diversos ambientes de transmissão de informações o protesto e a crítica que são feitos ao sistema de modo geral, em especial à política e aos governantes que regem esse sistema. As críticas são bem embasadas e utilizam argumentos persuasivos e lógicos para convencer o leitor e variam desde artigos, colunas jornalísticas, opiniões de especialistas à sátira e à ironia, maneira de chamar a atenção do leitor explorando o riso e sarcasmo usados como meio para criar conexão com o leitor e convencê-lo a aderir às ideias do discurso. O número de jornais televisivos e impressos que estão utilizando a sátira enquanto elemento crítico do discurso tem crescido abundantemente e uma das formas utilizadas pelos meios de comunicação para fazer uma crítica diferenciada e que chame a atenção do leitor é a charge. Para se entender melhor o porquê da utilização do gênero charge é importante saber qual sua definição e suas características:

O termo charge é francês, vem de charger, carregar, exagerar e até mesmo atacar violentamente (uma carga de cavalaria). Este tipo de texto tem caráter temporal, pois trata do fato do dia.(...) A charge será alvo do estudo por trazer, em uma análise superficial, implícita a história e a presença do interdiscurso. Ela é o local escolhido pela ironia, metáfora (transferência), pelo contexto, pelo 
sujeito, para atuar. Por ser combativa, tem lugar de destaque em jornais, revistas e na Internet. Portanto, ampla poderá ser a leitura interpretativa por nela se constatar a presença da linguagem, da história e da ideologia (SILVA, 2004, p. 13).

Na visão de Mouco, charge é

[...] crítica humorística de um fato ou acontecimento específico. É a reprodução gráfica de uma notícia já conhecida do público, segundo a percepção do desenhista. Apresenta-se tanto através de imagens quanto combinando imagem e texto. (MOUCO,2007, p. 5)

Sendo assim, é possível chegar-se a conclusão de que a charge utiliza a ironia e a sátira para produzir o riso e, através dela busca-se criticar a atuação de sujeitos sociais, tendo como destaque os governantes políticos. Mas, para que o objetivo da charge se concretize, os chargistas utilizam o recurso da derrisão que conforme Bonnafous (2003) apud BENITES (2010, p.154) "consiste na associação do humor e da agressão que a caracteriza e a distingue, em princípio da pura injúria”.

Pode-se então dizer que o texto chargístico é caracterizado pelo "exagero" com que são retratados os personagens, cujo recurso visa ao ataque crítico a determinados temas sociais e políticos, ao mesmo tempo em que provoca o riso por meio do humor. Trata-se de uma associação entre o texto verbal e o pictórico.

Este tipo de gênero apresenta uma certa quantidade de recursos lingüísticos; no entanto, é bastante comum em algumas charges o desenho de um balão com apenas um sinal de pontuação ( ou a pontuação apenas). Sendo assim, a pontuação deve ser entendida não só como elemento necessário à produção textual, mas também com elemento gráfico que compõe e estrutura a imagem. Enfim, deve-se considerar os elementos da sintaxe visual a partir dos elementos constituintes da imagem: cor, ritmo, volume, composição direção e, a partir desses aspectos, adotar um método de leitura das imagens de sentido (SOUZA, MACHADO, 2005, p. 59).

$\mathrm{Na}$ charge tudo significa, imagem e escrita se "completam na produção dos efeitos de sentido" (SOUZA, MACHADO, 2005, p. 59).O traçado das letras que compõem o verbal, a forma dos balões que representam a fala, sinais de pontuação, expressões faciais, cores, enfim todos os elementos estão carregados de significação e devem ser observados atentamente para tornar a leitura mais eficiente.

É importante destacar que, por ser um texto que agrega recursos lingüísticos, discursivos e gráfico-visuais, muitas vezes é necessário que o leitor disponha de um conhecimento mais profundo sobre o tema abordado, caso contrário, sua leitura poderá ficar restrita ao cômico, deixando assim de atingir o objetivo da charge, que é a crítica por meio do humor. Neste sentido, pode-se afirmar que é a intertextualidade é característica frequente no gênero charge, uma vez 
que, para que haja uma melhor compreensão do tema abordado na charge será necessário que o leitor faça inferências com outros textos já anteriormente lidos: “...a intertextualidade diz respeito aos modos como a produção e recepção de um texto dependem do conhecimento que se tenha de outros textos com os quais ele, de alguma forma, se relaciona. (KOCH, 200o).”

Outra característica marcante da charge é a presença da polifonia, ou seja, as várias vozes que participam do processo dialógico. A polifonia se define,segundo Bakhtin, pela convivência e pela interação, em um mesmo espaço do romance, de uma multiplicidade de vozes e consciências independentes e imiscíveis. Dessa maneira, as atividades do leitor e do escritor se intercambiam, resultando em um tecido de significados tramado por ambos. Assim, por meio da imagem que é de rápida leitura, a charge jornalística atrai a atenção do leitor, pois, com caráter polifônico este gênero tem o poder de conduzir diversas informações de maneira concisa, provocando através do humor crítico a reflexão do leitor sobre a atualidade sócio-político-econômica do país. Romualdo salienta que:

A charge é um tipo de texto que atrai o leitor, pois, enquanto imagem é de rápida leitura, transmitindo múltiplas informações de forma condensada. Além da facilidade de leitura, o texto chárgico diferencia-se dos demais gêneros opinativos por fazer sua crítica usando constantemente o humor.

(ROMUALDO, 2000, p.5)

No entanto, o leitor do texto chargístico tem que estar bem informado acerca do tema abordado, para que possa compreender e captar seu teor crítico. Afinal, ali está focalizada e sintetizada certa realidade. E somente os que conhecem essa realidade efetivamente entendem a charge.

Se o leitor do texto chárgico é um indivíduo bem informado, integrado nas questões e acontecimentos políticos de sua época, há a possibilidade de que ele compreenda e capte o teor crítico de algumas charges, sem ler os outros textos presentes no jornal, com os quais elas se relacionam intertextualmente. Mas se ele não conhece o fato, a situação ou personagens presentes na charge, ou se ainda deseja precisar as informações acessórias, buscará o auxílio dos textos que mantêm relações com o chárgico (ROMUALDO, 200o, p. 42).

Considerando o caráter informativo e opinativo das charges e sua ampla circulação social, é interessante proceder a uma análise criteriosa a respeito dos elementos que determinam a produção de sentidos dessas charges, de modo a instaurar um processo de análise discursiva desse fenômeno midiático em sala de aula, uma vez que charge pode ser vista não só como arte objetivando o riso, mas como prática política e formadora de opiniões acerca dos acontecimentos sociais. 


\section{A charge em sala de aula}

$\mathrm{Na}$ era da tecnologia, em que a internet tem se constituído como um importante atrativo para o público jovem, é importante que os professores busquem métodos eficientes para acompanhar não só a velocidade das informações, como maneiras de fazer com que o aluno se sinta atraído pela sala de aula. Os livros didáticos, não há que se negar, são importantes ferramentas em sala de aula, mas não se pode esquecer que existem outros meios imprescindíveis para a expansão do conhecimento como: as revistas, internet, jornais, etc. Esse conjunto de possibilidades de interação quando trabalhados dentro das necessidades dos alunos em sala de aula, tornam-se métodos eficazes no processo ensino-aprendizagem.

Considera-se que, vivenciando a era de comunicação e informação, a sociedade não mais consente leituras que tenham como finalidade uma única interpretação, estável e universal, nem mesmo leitores somente de livros. Ao oposto, na atualidade é cada vez mais preciso que o sujeito seja competente para entender as diversas linguagens e os múltiplos códigos que o cercam como, por exemplo, pintura, cinema, teatro, propaganda, histórias em quadrinhos, charges, dentre outros. Mas, para que o emprego de gêneros textuais exerça um papel relevante na formação dos discentes é imprescindível que o educador faça valer o seu compromisso de formar o educando em um sujeito ativo, capaz de analisar e articular com criticidade sobre vários temas em voga na sociedade, bem como, a produzir conhecimento.

Para tanto, faz-se necessário que, não somente o professor, mas todo o corpo técnico da instituição de ensino e a comunidade interajam na elaboração e difusão de projetos sócioeducacionais. Tais projetos devem viabilizar o progresso aprimorado do leitor, possibilitando-o a interpretar estilos textuais mais simples até a compreensão de gêneros discursivos mais complexos.

Dessa forma, pode-se dizer que a lingua(gem) adquirida pelo contexto social se desenvolve por completo através do processo de ensino-aprendizagem que, segundo as Diretrizes Curriculares Nacionais(2008), deve estar em consonância com as práticas discursivas:

No processo de ensino-aprendizagem, é importante ter claro que quanto maior o contato com a linguagem, nas diferentes esferas sociais, mais possibilidades se tem de entender o texto, seus sentidos, suas intenções e visões de mundo. A ação pedagógica referente à linguagem, portanto, precisa pautar-se na interlocução, em atividades planejadas que possibilitem ao aluno a leitura e a produção oral e escrita, bem como a reflexão e o uso da linguagem em diferentes situações. Desse modo, sugere-se um trabalho pedagógico que priorize as práticas sociais. (Diretrizes Curriculares de Língua Portuguesa, 2008, p. 55)

Nesta perspectiva depreende-se que a instituição de ensino está intrinsecamente valorada como um espaço onde se presume existir uma infinidade de ideias e opiniões voltados para o 
ensino-aprendizagem através de (re)inovações, a saber, a utilização de charges. Tais diretrizes enquadram - se em um referencial teórico voltado na essência a pedagogia histórica - crítico social em uma abordagem que valoriza a escola como espaço social democrático de direitos, responsável pela apropriação crítica e histórica do conhecimento como mecanismo de compreensão das relações interpessoais e para a transformação da realidade. E sua proposta se baseia na corrente sociológica e nas teorias de Bakhtin, que compreendem a língua como discurso.

Dentre as diversas linguagens que fazem parte do mundo contemporâneo, existe uma que integra linguagem escrita e linguagem visual: a Charge. Ela vem se solidificando como uma relevante ferramenta de difusão cultural e de formação educacional para pessoas de diferentes faixas etárias. A aplicabilidade da charge em um recinto educacional pode vir a ser um exercício copiosamente singular e interessante, uma vez que se trata de uma atividade que desperta o raciocínio e a interatividade entre os discentes permitindo uma aprendizagem aprazível e dinâmica.

A utilização da charge tem o propósito de justapor e formular conceitos, opiniões e princípios não somente da esfera de saber do educando, mas abrangendo outras visões de mundo. Nesse contexto espera-se que o ensino-aprendizagem não seja efêmero, mas sim duradouro e evolutivo, perpassando pelas etapas da vida estudantil do discente. A primazia da charge está em aderir uma imagem a um texto, com o intento de estimular o raciocínio do educando, permitindo que ele possa depreender e criticar o que sucede em seu meio e no mundo. Dessa forma o estudante poderá debater com discernimento e criticidade as normas e os padrões que estão sendo ministrados nas instituições de ensino, e os que estão sendo veiculados pela mídia (rádio, televisão, internet, jornais, revistas e outros).

Outro aspecto importante na utilização de tais recursos é a sua proximidade com o cotidiano, pois estes são geralmente encontrados em jornais e revistas, tratando temas atuais, atemporais, divertindo e marcando épocas. Além disso, permite que o aluno passe a entender a imagem como discurso, atribuindo-lhe sentidos sociais e ideológicos. É válido ressaltar ainda que a charge também serve como incentivo para a leitura de outros textos presentes em jornais e revistas nos quais o referido gênero é publicado, possibilitando assim atividades mais dinâmicas, interessantes, bem como desenvolve no aluno o empenho pela leitura e pela busca de novas informações. Além disso, ela tem muitas vezes o poder de influenciar o interlocutor, incutindo nele a ideologia presente na charge, com o fulcro de torná-lo mais consciente da realidade, já que esse é um dos objetivos da escola, ou seja, a educação precisa estar voltada para a formação de cidadãos capazes não só de entender a realidade, mas também de intervir nela.

Por essa razão, o professor deve manter-se sempre atualizado para exercer sua função 
enquanto formador de opinião,direcionar o aluno para que este possa compreender que existem outras possibilidades além do seu conhecimento de mundo, ou seja, que possa compreender que há outras realidades a serem esgotadas. Desse modo, acredita-se que a multimodalidade existente nas Charges possibilite e estimule os educandos à prática da leitura, uma vez que o contato com esse gênero textual, leve e agradável, possibilita uma intimidade com o ato de ler. É por meio das charges que uma grande parte das crianças e dos adolescentes passam a conhecer as linguagens plásticas desenhadas e com narrativas ou sem, iniciando seu contato com linguagem cinematográfica e a literatura, e adquirindo, assim, o gosto pela leitura.

Para Oliveira, "Os textos de charge ganham mais quando a sociedade enfrenta momentos de crise, pois é a partir de fatos e acontecimentos reais que o artista tece sua crítica num texto aparentemente despretensioso".(Oliveira, 2001, p. 265). A partir do registro acima, pode-se afirmar que a charge faz parte da história-memória de um determinado país ou estado, funcionando como uma espécie de registro crítico e opinativo da história imediata de um grupo social e, para que o leitor fazer uma interpretação correta da charge, será necessário que ele tenha uma memória social, a qual será acionada no momento da leitura, permitindo-lhe assim construir os possíveis sentidos para o discurso do qual esta é portadora. Reafirmando a importância histórica para difusão do conhecimento e (re)construir a memória de um povo Oliveira afirma que:

[...] os textos chargísticos constituem, por isso, uma vasta memória social, sem a qual não poderia haver História, que só se constitui pelo discurso. E ainda: “o que merece destaque, porém, é a imprescindível relação do fato histórico com o texto chargístico, este, por recuperar aquele, torna-o memorável. (OLIVEIRA, 2001, p. 265)

Assim, o professor pode propor atividades que possibilitem aos alunos a reflexão crítica sobre os fatos noticiados. Neste contexto, há a contra-palavra, ou seja, a resposta dos alunos às atividades de leitura de charges propostas, o seu posicionamento diante do conteúdo temático e das sátiras ao momento atual político-social brasileiro. Posta na sala de aula, a charge ajuda a subsidiar a competência argumentativa dos estudantes a partir de relações lógico-discursivas e críticas sociais trazidas à tona por ela e, pelo fato de provocar o humor, promove uma atividade prazerosa para alunos e professores.

A construção da charge pode fundamentar-se na remissão a outros textos que se configuram em linguagem verbal e não verbal. O que a torna diferente é o seu caráter original e a forma perspicaz de demonstrar sua capacidade de aglutinar divergentes temas, na qual, afirma e nega concomitantemente suas ideias, direcionando o leitor a refletir sobre os acontecimentos do mundo contemporâneo e a interagir através de uma superposição textual. 
As charges utilizadas em um ambiente de ensino podem desempenhar o papel de transmissoras dos bons costumes e ações no convívio social, se produzida para esta finalidade. Para isso, é preciso que a charge deixe de ser praticada e vista unicamente, com o objetivo de ironizar os políticos e a politicagem existente na sociedade. No processo de seleção das charges para fins pedagógicos, faz-se necessário que dêem a elas um novo sentido, uma nova visão, buscando difundir valores morais, a saber; respeito, cidadania, bons hábitos e educação, os quais poderão ser debatidos, ainda que de forma irônica, tendo-se a precaução de não abster se de seu cunho pedagógico.

É importante que o docente evite a utilização de charges com conteúdos que possam ultrajar religiões, culturas e etnias. Recomenda-se tal restrição porque em um ambiente escolar há necessidade de atentar para a idade cronológica e o desenvolvimento mental dos discentes. Ademais, o que se espera da charge é o rendimento no ensino-aprendizagem alcançado pela utilização dessa metodologia em sala de aula, pois optar pelo uso desses tipos de texto é fomentar no aluno um olhar mais cuidadoso para tudo que o cerca e contribuir para que a escola tenha novas perspectivas de ensino.

\section{CONSIDERAÇÕES FINAIS}

É de conhecimento geral que a Escola participa de um difícil processo de adequação em relação à sociedade atual, assumindo novos valores sociais e novos ideais. Além disso, a Escola, antes tida como uma única alternativa para aquisição de novos conhecimentos, passa agora a ser gradativamente substituída e concorre com novas tecnologias, sendo destinado a ela o papel de figurante e muitas vezes até de antagonista. Sabe-se que a concorrência entre as novas tecnologias, como a internet, e a escola é altamente injusta, tendo em vista que são muitos os atrativos daquela em relação a esta. $\mathrm{O}$ uso das imagens, do som, da praticidade e da instantaneidade na comunicação são recursos ainda raros ou quase nunca utilizados como um instrumento de trabalho pela maioria dos docentes em sala de aula.

Por esse motivo o uso das charges e de aspectos humorísticos em sala de aula tende a facilitar a comunicação entre professor e aluno, sendo uma alternativa de aproximação dos conteúdos de determinada disciplina com o quotidiano vivenciado pelo discente. Tendo a charge como uma "aliada", o professor pode auxiliar no desenvolvimento tanto da capacidade interpretativa do aluno quanto do senso crítico, sem que haja um didatismo. Através da imagem, a charge consegue transmitir mensagens que serão inferidas pelos próprios alunos, que a contextualizarão, utilizando o seu conhecimento prévio e percebendo-se como "peça" importante no processo de aprendizagem. $\mathrm{O}$ uso da linguagem não-verbal em sala de aula estimula o aluno 
dos nossos dias, que é constantemente exposto a imagens e influenciado por elas, sem ser capaz de ler criticamente o que lhe é apresentado.

Assim, cabe aos professores fazerem uso do não verbal com o objetivo de desenvolver o senso crítico do aluno e possibilitar que a imagem funcione também como um atrativo para a apreensão de novos conhecimentos e questionamentos acerca do mundo no qual está inserido.

A importância da charge no ensino é algo cada vez mais evidente, podendo ser comprovada pelo uso constante desse recurso em vestibulares das melhores universidades públicas de todo o Brasil. A transformação já é visível em processos seletivos, embora, muitos docentes ainda insistam em restringir o ensino a leituras de frases soltas ou a listas com nomes e datas a serem decoradas. Desta forma, pode-se chegar a conclusão de que optar pelo uso desse gênero textual é fomentar no aluno um olhar mais cuidadoso para tudo que o cerca e contribuir para que a escola tenha novas perspectivas de ensino.

Para que se crie perspectivas inovadoras, faz-se necessário que o professor seja, antes de tudo, um pesquisador,capaz de investigar novas possibilidades de ensinar e estar pronto para modificar esse ato diante dos resultados de sua experiência. Todos os gêneros textuais podem e devem ser empregados pelo professor, mas é importante que sejam adequados de acordo com o público ao qual se dirige.

A aula de Língua Portuguesa não pode ficar restrita ao ensino da gramática, mais precisamente da gramática normativa, assim como a aula de História não se restringe a datas e nomes,ou a Geografia a países e suas capitais. Ou seja, o uso da charge surge como uma forma de acompanhar as transformações na sociedade, e, consequentemente, as da língua, sendo intolerável que a escola também não passe por um processo de intensas modificações. O ensino, não só de Língua Portuguesa, mas de todas as demais disciplinas, deve ter ao seu alcance todos os recursos possíveis, não havendo prioridade entre um e outro, pois,todos possuem seu grau de importância.

A necessidade de saber ler todos os códigos sejam eles verbais ou não-verbais também deve ser suprida nas escolas. $O$ aprendizado da língua se faz dia-a-dia, enquanto estamos folheando revistas, passando por um outdoor, contando uma piada, sem que esse processo de aprendizagem seja percebido. A aula de português pode incitar a curiosidade do aluno, mostrando que a interpretação e a discussão sobre temas atuais pode ser algo prazeroso e natural. Embora seja uma árdua tarefa, é necessário tornar satisfatório e eficiente o ensino da disciplina de língua portuguesa, valendo-se de variadas formas de transmitir conhecimento e da linguagem tanto verbal quanto não-verbal.

Desvendar esse universo de interpretações e opiniões que se apresenta através das 
charges, é sempre sedutor e prazeroso em qualquer nível de ensino, porque trazem o perfil da sociedade e seus acontecimentos para dentro da escola. Assim, os alunos conseguirão estabelecer uma relação entre o texto e a realidade, ou seja, é a aula ajudando a prepará-los para a vida e para a cidadania. Além do mais, esse tipo de construção serve, primorosamente, para ser aplicado em sala de aula, pela curiosidade que suscita, graças à articulação de diferentes e envolventes procedimentos textuais, cumprindo as expectativas didáticas.

A apresentação da charge e das histórias em quadrinhos emerge como uma forma de junção de conceitos, conteúdos e normas ao conhecimento de mundo do discente, transformando o aprendizado em algo duradouro, ou seja, que se mantém e evolui a partir das novas informações que o aluno constrói ao longo de sua formação acadêmica.

Através deste trabalho, espera-se ter demonstrado que a Escola pode e deve ser um espaço privilegiado para o entendimento do discurso midiático, assim como para desenvolver a leitura da charge e formar a opinião, partindo-se da premissa que ensinar a língua sugere ensinar o domínio de diversos gêneros do discurso e, também, gêneros das instâncias públicas de uso da linguagem, tornando este um relevante processo, provocando um confronto dialógico entre diferenciadas posições apresentadas pelos sujeitos na escola.

\section{REFERÊNCIAS}

BAKHTIN, Mikhail. Estética da Criação Verbal. São Paulo: Martins Fontes, 2003.

BENITES, Sonia Aparecida Lopes. Sentido, História e Memória em Charges Eletrônicas: os domínios do interdiscurso. In: POSSENTI, Sírio; PASSETI, Maria Célia (Orgs). Estudos do texto e do discurso: política e mídia. Maringá: Eduem, 2010.

BRASIL. Secretaria de Educação Fundamental. Parâmetros Curriculares Nacionais: terceiro e quarto ciclos do ensino fundamental - 5 a 8 $^{\mathbf{a}}$ séries: língua portuguesa. Brasília: MEC/SEF, 2008.

CHIAPPINI, L. (org.). Aprender e ensinar com textos não escolares. São Paulo: Cortez, 1997.

KOCH, Ingedore Villaça. O texto e a construção dos sentidos. São Paulo: Contexto, 2000.

MACHADO, I. Gêneros discursivos. In: BRAIT, Beth. (Org). Bakhtin: conceitos-chave. São Paulo: Contexto, 2005.

MARCUSCHI, L.A. Gêneros textuais: definição e funcionalidade. In; Gêneros textuais e ensino. Rio de Janeiro: Lucena, 2003. 
MOUCO. Maria aparecida Tavares. Leitura, análise e interpretação de charges Com fundamentos na teoria semiótica. Disponível em http://www.diaadiaeducacao.pr.gov.br/portals/pde/arquivos/IIo4-4.pdf, acesso em 30.II.20II.

OLIVEIRA, M.L.S. Charge: imagem e palavra numa leitura burlesca do mundo. In: AZEREDO, J. C. Letras \& Comunicação: uma parceria para o ensino de língua portuguesa. Petrópolis: Vozes, 200I.

ROMUALDO, E. C. Charge jornalística: intertextualidade e polifonia: um estudo de charges da Folha de São Paulo. Maringá, PR: Eduem, 2000.

SILVA, Carla Letuza Moreira e. O trabalho com charges na sala de aula. Pelotas, RGS: UFRGS, 2004 .

SOUZA, Maria Irene Pellegrino de Oliveira; MACHADO, Rosemeri Passsos Baltazar. O verbal e não-verbal na produção dos efeitos de sentido no gênero charge. In: CRISTÓVÃO, Vera Lúcia Lopes, 2010.

XAVIER, Antonio Carlos; CORTEZ, Suzana(Orgs.). Conversas com lingüistas: virtudes e controvérsias da lingüística. São Paulo: Editoria: Parábola, 2003. 